\title{
Evaluación de materiales de encalado mediante pruebas de incubación en un oxisol de la altillanura colombiana
}

\author{
Evaluation of liming materials using incubation tests in an oxisol from the Colombian highlands
}

\section{Hugo Castro'; Juan Carlos Guerrero²}

1 I.A., M.Sc., Profesor Titular Programa de Ingeniería Agronómica, Universidad Pedagógica y Tecnológica de Colombia, Tunja, Colombia, hcastrofranco@gmail.com.

2 I.A., Investigador Gissat, Universidad Pedagógica y Tecnológica de Colombia, Tunja, Colombia, carlos_yeyz@hotmail.com.

Citar: Castro, H. \& Guerrero, J. (2018). Evaluación de materiales de encalado mediante pruebas de incubación en un oxisol de la altillanura colombiana. Revista de Ciencias Agrícolas. 35(2): 14-26 doi:http:// dx.doi.org/10.22267/rcia.183502.88

Recibido: febrero 22 de $2017 . \quad$ Aceptado: agosto 03 de 2018.

\section{RESUMEN}

Los 0xisoles comprenden una de las fronteras agrícolas más extensas del mundo; en América del Sur existen 243 millones de hectáreas, 17 corresponden a Colombia. La acidez debida al aluminio, la desbasificación y la baja disponibilidad de fósforo, constituyen los indicadores de infertilidad química más relevantes en estos suelos. El objetivo del presente trabajo, fue evaluar el efecto de materiales de encalado sobre la acidez y el mejoramiento químico de bases en un oxisol típico de sabana nativa, ubicado en la Altillanura Colombiana. Mediante un diseño experimental completamente aleatorio se definieron 13 tratamientos de incubación con tres replicaciones. Se tuvo en cuenta la caracterización química del suelo problema, al cual se incorporó 1.5 t.ha ${ }^{-1} \mathrm{CaCO}_{3}$ equivalente utilizando diferentes materiales de encalado comerciales de $\mathrm{EQCaCO}_{3}$ conocido. A los 40 días post-incubación se evaluaron variables químicas relacionadas con la problemática de acidez ( $\mathrm{pH}$ y concentraciones de $\mathrm{Ca}^{2+}, \mathrm{Mg}^{2+}$ y P). Se comprobó que los materiales encalantes usados como enmiendas simples (dolomitas calcinadas, dolomitas molidas, hidróxidos de calcio y magnesio, escorias básicas y cales vivas) presentarón efecto significativo sobre el control de la acidez y sobre el incremento en la concentración de $\mathrm{Ca}^{2+} \mathrm{y} \mathrm{Mg}^{2+}$ coloidal. Similar respuesta se obtuvo cuando los tratamientos relacionados como enmiendas simples, se mezclaron con roca fosfórica y materia orgánica (gallinaza) en relación porcentual 75:10:15 respectivamente. Los hidróxidos de calcio y magnesio y las escorias básicas de siderúrgica usadas como enmiendas simples o formando parte de enmiendas complejas, ofrecieron efectos superiores en el control de acidez con respecto al resto de materiales.

Palabras clave: acidez del suelo, encalado, mejoramiento químico, pruebas de incubación. 


\section{ABSTRACT}

Oxisols form one of the broader agricultural frontiers in the world; in South America, there are 243 million hectares, with 17 million in Colombia. Acidity resulting from aluminum, debasification and low availability of phosphorus are the most relevant indicators of chemical infertility in these soils. The objective of the present study was to evaluate the effect of liming materials on controlling acidity and chemical improvement of bases in an oxisol typical of the native savanna in the Colombian Altillanura. Using a completely randomized experiment design, 13 incubation treatments with three replications were defined. The chemical characterization of the problem soil, to which 1.5 t.ha $^{-1} \mathrm{CaCO}_{3}$ equivalent was incorporated using different commercial $\mathrm{EQCaCO}_{3}$ liming materials, was determined. At 40 days postincubation, the chemical variables related to acidity ( $\mathrm{pH}$ and concentrations of $\mathrm{Al}^{3+}, \mathrm{Ca}^{2+}, \mathrm{Mg}^{2+}$ and $\mathrm{P}$ ) were evaluated. The encapsulating materials using simple amendments (calcined dolomites, ground dolomites, calcium and magnesium hydroxides, basic slag and live limes) had a significant effect on the control of acidity and increased the concentrations of $\mathrm{Ca}^{2+}$ and colloidal $\mathrm{Mg}^{2+}$. A similar response was obtained when the treatments, such as the simple amendments, were mixed with phosphoric rock and organic matter (chicken manure) at a ratio of 75:10:15, respectively. The calcium and magnesium hydroxides and the basic steel slag, used as simple amendments or as part of complex amendments, offered superior effects on controlling acidity, with respect to the rest of the materials.

Keywords: soil acidity, liming, chemical improvement, incubation tests.

\section{INTRODUCCIÓN}

La acidificación es un proceso normal de los suelos, promovido por diferentes causas, entre las cuales se incluyen, la mineralización de la materia orgánica, la disminución de bases intercambiables en el suelo ( $\mathrm{Ca}, \mathrm{Mg}$ y $\mathrm{K}$ ) por absorción de la planta, la aplicación de fertilizantes a base de nitrógeno y azufre y la presencia de aluminio intercambiable por evolución genética del suelo (Lora, 2010). La acidez aumenta con el aumento del proceso de meteorización, llegando a generar $\mathrm{pH}^{\prime} \mathrm{s}$ de reacción extremadamente ácida y a formar horizontes pedogenéticos profundos de color rojizo (horizontes óxicos), que son criterio diagnóstico para la clasificación científica de los suelos oxisoles (Soil Survey Survey Staff, 2014). En América del Sur, estos suelos pertenecen a sabanas tropicales, con una extensión de 243 millones de hectáreas, que llegan a constituir una de las fronteras agrícolas más extensas del mundo. Dentro de nuestro país, en los ecosistemas de sabana, predominan los suelos oxisoles, los cuales ocupan más de 17 millones de hectáreas, de éstos 4,26 millones se conocen como Altillanura Colombiana (Amezquita et al., 2013).

Estos suelos se han utilizado por varias décadas en ganadería extensiva. Su infertilidad química derivada de problemas de acidez y desbasificación como consecuencia de su estado avanzado de meteorización, restringe de forma significativa el desarrollo vegetal. A pesar que, en general, éstas áreas presentan condiciones favorables para la explotación agrícola como son pluviosidad, temperatura y una topografía apta para la mecanización, el suelo requiere adecuación mediante encalamiento para mitigar la toxicidad de aluminio y asegurar un mejoramiento en las concentraciones de calcio, magnesio y fósforo, que gradualmente restaure la fertilidad del suelo en su componente químico (Rivera et al., 2013).

A nivel mundial, desde hace muchos años y hasta la fecha, los problemas de acidez en los diferentes órdenes de suelos, se han venido 
corrigiendo con prácticas de encalamiento utilizando diferentes enmiendas simples $\mathrm{y}$ mezclas de estas para aumentar los niveles de $\mathrm{pH}$ y disminuir la acidez. Al respecto, Alvarez-Sanchez et al. (2013) utilizaron encalado y micorrizas en Andisoles; Castro y Munevar, (2013) reportan el efecto de mezclas combinadas de materiales encalantes en la rehabilitación de suelos sulfatados ácidos improductivos; en suelos oxisoles más exactamente en un Typic Haplorthox, Carmeis et al. (2017) utilizaron cal y fosfoyeso en aplicaciones individuales y en mezcla, encontrando mejores resultados con estas últimas. En un Rhodic Hapludox del sur de Brasil, Massao et al. (2016) aplicaron cal y yeso en combinación con labranza cero, hallando en estas prácticas una buena estrategia para mejorar la actividad biológica de suelo y la productividad agrícola. En un Ultisol ácido Masud et al. (2014) utilizaron cal, escorias básicas y materiales orgánicos, obteniendo mejores resultados en la combinación de las cales con los materiales orgánicos compostados; los autores consideran importante comentar sobre el uso del fosfoyeso en proporción del 15 al 25\% como fuente acompañante de enmiendas complejas, evaluaciones en pruebas de incubación explorando la aplicación de 1.5 t.ha-1 de fosfoyeso sobre el control de la acidez y la dinámica del calcio se han encontrado cambios no significativos del $\mathrm{pH}$ del suelo, pero sí, mejoramiento significativo en las concentraciones de calcio soluble.

Los requerimientos para la neutralización parcial o total de la acidez, pueden ser definidos con un criterio más técnico y preciso mediante curvas de encalamiento obtenidas a partir de pruebas de incubación (Epstein y Bloom, 2005). La prueba de incubación en laboratorio consiste en la adición de dosis crecientes de $\mathrm{CaCO}_{3}$ expresadas como equivalente químico (EQ) a cantidades constantes de suelo, donde como primera medida a la aproximación de las necesidades de encalamiento, se debe tener en cuenta la capacidad buffer del suelo, la cual puede variar de acuerdo con el material parental, contenido y tipo de arcilla, contenido de materia orgánica y presencia de óxidos e hidróxidos de hierro y aluminio (Marshner, 1995).

La elaboración de curvas de encalamiento bajo las variables químicas que intervienen en el manejo de la acidez, permiten definir las necesidades de cal en términos de t.ha ${ }^{-1} \mathrm{CaCO}_{3}$ equivalente que deben ser aplicadas al suelo problema mediante el uso de materiales de encalado de diferente composición y equivalencia química en $\mathrm{CaCO}_{3}$, ofertados en el mercado. Este método deducible de pruebas de incubación en laboratorio ha sido validado y extrapolado a campo por parte del Grupo de Investigación en Suelos Sulfatados Ácidos Tropicales (Castro y Gómez, 2015), como un enfoque de mayor contenido científico aplicable al manejo de la acidez en suelos agrícolas.

Dada la importancia y justificación expuesta alrededor del tema de la acidez del suelo y su control, la presente investigación tuvo como objetivo, probar el efecto correctivo y fertilizante de varios materiales de encalado de diferente composición y pureza química $\left(\mathrm{EQCaCO}_{3}\right)$, sobrelos cambios inducidos al $\mathrm{pH}$, la acidez intercambiable y las concentraciones de calcio, magnesio y fósforo de un suelo oxisol de sabana nativa representativo de la Altillanura plana Colombiana.

\section{MATERIALES Y MÉTODOS}

Las pruebas de incubación, como aspecto central de esta investigación, se realizaron en el Laboratorio de Suelos del Programa de Ingeniería Agronómica de la Universidad Pedagógica y Tecnológica de Colombia, sede Tunja. Se utilizó la capa arable (0$20 \mathrm{~cm}$ ) de un suelo de sabana nativa clasificado por los autores como Typic Hapludox, ubicado geográficamente en la región natural Orinoquía, subregión altillanura plana, paisaje de sabana nativa, sitio de recolección de la muestra Centro de 
Investigación Taluma (Corpoica). Climáticamente corresponde a un piso térmico cálido (altitud $160 \mathrm{msnm}$, temperatura $>24^{\circ} \mathrm{C}$ ) y un régimen de precipitación anual de $2400 \mathrm{~mm}$.

El método de investigación correspondió a una aplicación experimental demostrativa (estudio de caso) donde se contó primeramente con el análisis químico completo original del suelo problema. El diagnóstico interpretativo de la información analítica de dicho suelo mostró una problemática acentuada de acidez y desbasificación por cumplir con la totalidad de los criterios expuestos por Castro y Gómez (2010), en el sentido de que los problemas de acidez aumentan cuando se presentan las siguientes condiciones: $\mathrm{pH}<5,5$, acidez o aluminio intercambiable $>0,5 \mathrm{Cmol}_{c} \mathrm{Kg}^{-1} \mathrm{de}$ suelo, suma de bases $(\mathrm{Ca}+\mathrm{Mg}+\mathrm{K})<5 \mathrm{Cmol}_{\mathrm{c}} \mathrm{Kg}^{-1} \mathrm{de}$ suelo, saturación de acidez $\left(\mathrm{Al}^{3+}\right)>20 \%$ y tendencia a una baja disponibilidad de fósforo.

Para cumplir con el objetivo de la investigación dirigido al control de la acidez y la desbasificación del suelo, se probó el efecto de materiales de encalado de diferente composición y reactividad química (concepto relacionado con la pureza del material de encalado en términos de equivalente químico en $\mathrm{CaCO}_{3}$ ).

A continuación (Tabla 1), se relacionan los materiales de encalado comerciales empleados en la experimentación con su respectiva composición y $\mathrm{EQCaCO}_{3}$

Tabla 1. Composición y valor $\mathrm{EQ} \mathrm{CaCO}_{3}$ de los materiales utilizados.

\begin{tabular}{|c|c|c|c|c|c|c|}
\hline \multirow{2}{*}{ Nombre comercial } & \multicolumn{5}{|c|}{ Composición química (\%) } & \multirow[b]{2}{*}{$\mathrm{EQ} \mathrm{CaCO}_{3}$} \\
\hline & $\mathrm{CaO}$ & Mg0 & $\mathrm{CaCO}_{3}$ & $\mathrm{MgCO}_{3}$ & $\mathbf{P}_{2} \mathbf{O}_{5}$ & \\
\hline Dolomita molida Inferhuila & & & 55 & 33 & & 94 \\
\hline Dolomita calcinada Rio Claro & 60,9 & 32,2 & & & & 188 \\
\hline $\begin{array}{l}\text { Hidróxidos de calcio y magnesio } \\
\text { procedentes de la calcinación de } \\
\text { dolomitas de Tesali Fertipaez }\end{array}$ & 40 & 18 & & & & 157 \\
\hline $\begin{array}{l}\text { Escorias básicas de siderúrgica (sidenal) } \\
\text { procedentes del horno cuchara }\end{array}$ & 59 & 11 & & & & 132 \\
\hline $\begin{array}{l}\text { Cal viva cernida de Nobsa procedente de } \\
\text { la calcinación de la caliza de Nobsa }\end{array}$ & 75 & & & & & 134 \\
\hline Roca fosfórica de Fosfatos de Boyacá & 45 & & & & 30 & 73 \\
\hline
\end{tabular}


Mediante un diseño experimental completamente aleatorio, se definieron 13 tratamientos de incubación con tres replicaciones, incorporando al suelo problema lo correspondiente a 1.5 t.ha $^{-1} \mathrm{CaCO}_{3}$ equivalente a través de diferentes materiales de encalado comercial de $\mathrm{EQCaCO}_{3}$ conocido. Estos materiales se aplicaron como enmiendas simples (100\%) o mezclas de ellas con roca fosfórica y gallinaza en una relación porcentual 75:10:15 respectivamente (Tabla 2). Cada unidad experimental representada por $2200 \mathrm{~g}$ de suelo se sometió a prueba de incubación una vez adicionados los materiales de encalado correspondientes a cada tratamiento. El proceso de incubación se llevó a cabo bajo una temperatura de $20^{\circ} \mathrm{C}$, manteniendo el suelo a capacidad de campo en materos herméticamente sellados. Para monitorear los cambios químicos inducidos al suelo por efecto del encalamiento, se evaluaron la acidez $(\mathrm{pH}$, concentración disponible de $\mathrm{Al}, \mathrm{Ca}, \mathrm{Mg}$, P y concentración soluble de $\mathrm{Ca}, \mathrm{Mg}, \mathrm{P}$ ) a los 40 días después de someter el suelo a incubación.

Los métodos analíticos utilizados para evaluar las diferentes variables químicas en el estado exante y post-tratamiento del suelo estudiado fueron los siguientes: $\mathrm{pH}$ (método potenciométrico relación suelo-agua 1:1), acidez intercambiable (método de Yuang KCl $1 \mathrm{~N}$ ), Ca y Mg extractable (método de acetato de amonio $1 \mathrm{~N}$ y neutro y medición por absorción atómica), $\mathrm{P}$ disponible (método Bray II y medición colorimétrica), Ca soluble y Mg soluble (método Holandés relación suelo: agua 2:1 y cuantificación por absorción atómica). Para comparar los cambios inducidos al suelo por efecto de los tratamientos se representó gráficamente la tendencia de la respuesta obtenida para cada variable o parámetro químico, tomando como referencia el tratamiento control o testigo absoluto.

Tabla 2. Definición y descripción de los tratamientos experimentales

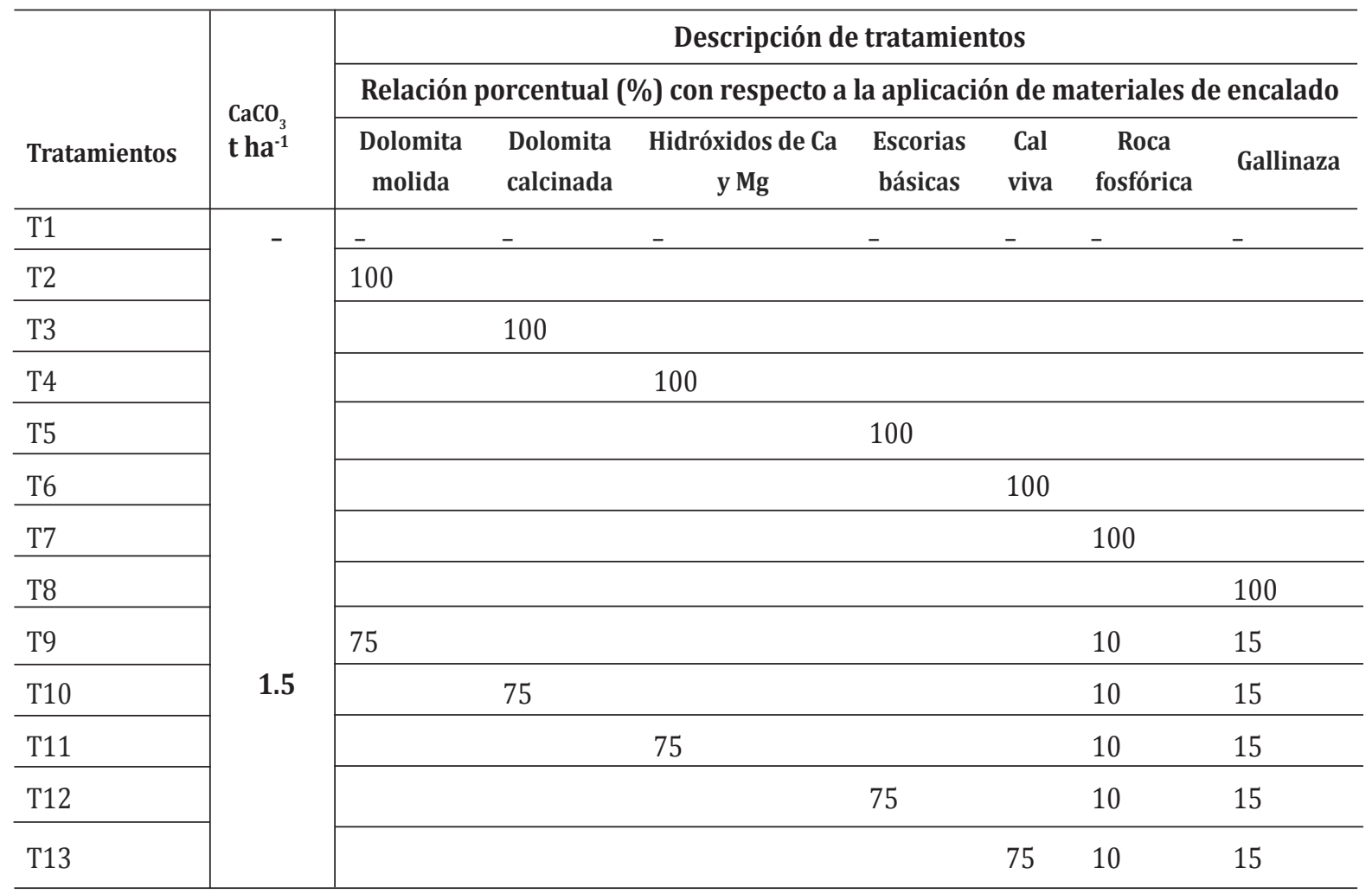

Nota: los tratamientos cuya aplicación corresponde al 100\% (T2, T3, T4, T5, T6, T7, T8) deben interpretarse como enmiendas simples. Los tratamientos resaltados (T9, T10, T11, T12, T13) corresponden a enmiendas complejas de relación porcentual 75:10:15, donde la roca fosfórica participa con el 10\% y la gallinaza con el 15\% de la mezcla total. T1 (testigo). 
Los resultados obtenidos se sometieron al Análisis de Varianza por medio del Software SAS V 9.4. Se realizaron pruebas de comparación de Tukey entre tratamientos para todas las variables, en las cuales se realizó la hipótesis nula.

\section{RESULTADOS Y DISCUSIÓN}

Condiciones iniciales del suelo. En la Tabla 3 , se muestran los resultados del análisis del suelo estudiado, el cual refleja su condición de fertilidad natural. Está condición inicial tomada en el experimento como testigo absoluto o control, reporta un suelo de muy baja fertilidad química, caracterizado por presentar en su capa arable $(0-20 \mathrm{~cm})$ una reacción muy fuertemente ácida $(\mathrm{pH}=4,86)$, saturación de aluminio del $51 \%$, bajos contenidos de bases intercambiables $\left(\mathrm{Ca}+\mathrm{Mg}+\mathrm{K}<5 \mathrm{Cmol}_{\mathrm{c}} \mathrm{Kg}^{-1}\right)$ y de fósforo disponible $(6,04 \mathrm{ppm})$. Los anteriores resultados, diagnostican una problemática severa de acidez y desbasificación, deducible de un suelo de carácter álico con muy baja CICE $\left(2.75 \mathrm{Cmol} \mathrm{Kg}^{-1}\right)$. Los altos contenidos de materia orgánica registrados en el análisis contribuyen de manera efectiva a amortiguar la baja fertilidad química de la fracción mineral del suelo. Los resultados encontrados correlacionan con las variables químicas de los suelos oxisoles descritos por Amezquita et al. (2013) para sabanas nativas de la altillanura Colombiana. Resultados similares encontraron Souza et al. (2017) al recopilar 179 análisis de suelos oxisoles para estudiar la asociación entre el carbono orgánico y los óxidos e hidróxidos de hierro y aluminio.
Resultados post incubación. Según el Análisis de Varianza, las variables evaluadas $\mathrm{pH}$, calcio $\mathrm{y}$ magnesio coloidal, magnesio soluble y fósforo disponible $\left(\mathrm{mg}, \mathrm{Kg}^{-1}\right)$ presentaron diferencias estadísticas con respecto al testigo, por efecto de la aplicación de los diferentes tipos de materiales de encalado, bien como enmiendas simples o mezclas de estas.

pH y control de la acidez. La Figura 1 muestra la tendencia registrada sobre el comportamiento de la reacción del suelo $(\mathrm{pH})$ posterior a la incorporación de las enmiendas o correctivos de acidez y de haber sometido el suelo a incubación.

Los valores menores de pH se obtuvieron en el T8, con la aplicación de gallinaza, en este caso, se registró una reacción fuertemente ácida $(\mathrm{pH}=5,3)$ con mínimas concentraciones de aluminio intercambiable. Aunque la aplicación de abono orgánico tipo gallinaza en dosis de 1.5 t.ha $^{-1}$ registró uno de los valores de pH más bajos, se comprobó que controla acidez y aumenta el $\mathrm{pH}$ con respecto al tratamiento control. Materechera y Mkhabela (2002) también encontraron que la aplicación de abono orgánico tipo gallinaza puede ser usado como enmienda para la neutralización de la acidez intercambiable, aunque afirman que presentan más efectividad las cales agrícolas. De otra parte, Hagvall et al. (2015) encontraron que esto se debe a la formación de complejos del aluminio con los radicales libres de la materia orgánica $(\mathrm{Al} / \mathrm{r}-\mathrm{COOH})$, los cuales se incrementa a un rango de $\mathrm{pH}$ de 3 a 6 y alta acidez, características que presenta el suelo de estudio.

Tabla 3. Análisis químico inicial del suelo estudiado

\begin{tabular}{|c|c|c|c|c|c|c|c|c|c|c|c|c|c|c|c|}
\hline \multicolumn{4}{|c|}{ Acidez } & \multicolumn{5}{|c|}{$\begin{array}{c}\text { Bases intercambiables } \\
\left(\mathrm{Cmol.kg}^{-1}\right)\end{array}$} & \multirow[b]{2}{*}{$\begin{array}{l}\% \\
\text { MO }\end{array}$} & \multirow[b]{2}{*}{$\begin{array}{c}\mathrm{P} \\
(\mathrm{mg} . \\
\left.\mathrm{kg}^{-1}\right)\end{array}$} & \multicolumn{5}{|c|}{$\begin{array}{c}\text { Elementos menores } \\
\left(\mathrm{mg} \cdot \mathrm{kg}^{-1}\right)\end{array}$} \\
\hline $\mathrm{pH}$ & $\begin{array}{r}\mathrm{Ac} \\
(\mathrm{Cm} \\
\mathrm{Al}^{3+}\end{array}$ & $\begin{array}{l}\text { ter. } \\
\mathrm{Kg}) \\
\mathrm{H}^{+}\end{array}$ & $\% \mathrm{Al}^{3+}$ & $\mathrm{Ca}$ & $\mathrm{Mg}$ & K & $\mathrm{Na}$ & $\begin{array}{c}\mathrm{Ca}+\mathrm{Mg}+\mathrm{K} \\
\text { Criterio } \\
\text { Desbasificación }\end{array}$ & & & $\mathrm{Fe}$ & $\mathrm{Mn}$ & $\mathrm{Cu}$ & $\mathrm{Zn}$ & B \\
\hline 4,86 & 1,4 & 0,4 & 51 & 0,6 & 0,25 & 0,06 & 0,04 & 1,39 & 3,62 & 6,04 & 88 & 0,74 & 0,02 & 3,64 & 0,3 \\
\hline
\end{tabular}

Fuente: Laboratorio de Suelos y Aguas, servicio a la comunidad, Programa de Ing. Agronómica, UPTC-Tunja 


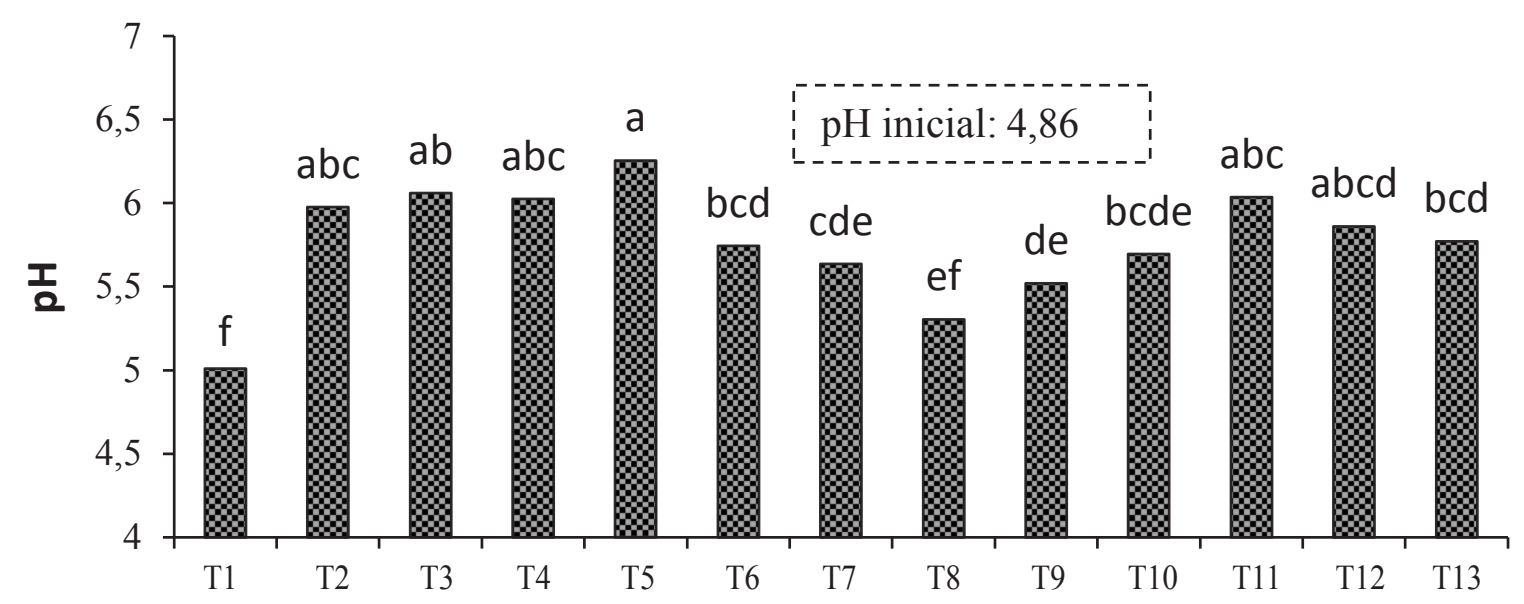

T1: Testigo; T2: dolomita molida; T3: dolomita calcinada; T4: hidróxidos de Ca y Mg; T5: escorias básicas; T6: cal viva; T7: roca fosfórica; T8: gallinaza; T9; dolomita molida, roca fosfórica y gallinaza; T10: dolomita calcinada, roca fosfórica y gallinaza; T11: hidróxidos de Ca y Mg, roca fosfórica y gallinaza; T12: escorias básicas, roca fosfórica y gallinaza; T13: cal viva, roca fosfórica v gallinaza.

Figura 1. Comportamiento del pH por efecto de los materiales de encalado después de 40 días de la incubación. Medias con la misma letra no difieren significativamente.

Con respecto al efecto de las enmiendas calcáreas simples, se encontró que a dosis de 1,5 tha $^{-1} \mathrm{CaCO}_{3}$ equivalente, todas superaron el $\mathrm{pH}(4,86)$ original del suelo, con diferencias altamente significativas respecto al testigo. El mejor resultado se obtuvo con el grupo de enmiendas referenciadas por los tratamientos (T2, T3, T4, T5, T6) que registraron pH's de 6. Según Castro et al. (2006), esto representa la condición óptima para garantizar la neutralización de la acidez activa e intercambiable del suelo estudiado. Similar respuesta se obtuvo cuando los tratamientos anteriormente relacionados como enmiendas simples, se mezclaron con roca fosfórica y materia orgánica (gallinaza) en la relación porcentual 75:10:15 respectivamente (T9, T10, T11, T12, T13). Al respecto, Sarma et al. (2017) encontraron que la adición de biochar o carbón vegetal empleado como enmienda en agricultura de suelos ácidos, podría ser una opción sustentable para aumentar la productividad de estos suelos.
Se destaca el empleo de los hidróxidos de calcio y magnesio de Tesalia (T4, T11) y las escorias básicas de siderúrgica (T5, T12), bien como enmiendas simples o formando parte de enmiendas compuestas o complejas, porque a igual dosis ofrecieron efectos superiores en el manejo de acidez con respecto al resto de materiales. El T5 (aplicación de escorias básicas) presentó el mayor valor de $\mathrm{pH}$ 6,26 y estadísticamente existen diferencias con respecto a los demás tratamientos, resultado que concuerda con lo afirmado por Wang et al. (2013) al concluir que la aplicación de escorias básicas es un método que reduce saturación de aluminio y aumenta el pH en suelos ácidos.

Calcio coloidal y soluble. El análisis de los resultados obtenidos sobre la dinámica del calcio referida a lo ocurrido con las formas coloidales y solubles del elemento, posterior a la incorporación de los materiales de encalado, se presenta en la Figura 2 y Figura 3. Los aspectos más relevantes se señalan a continuación: 


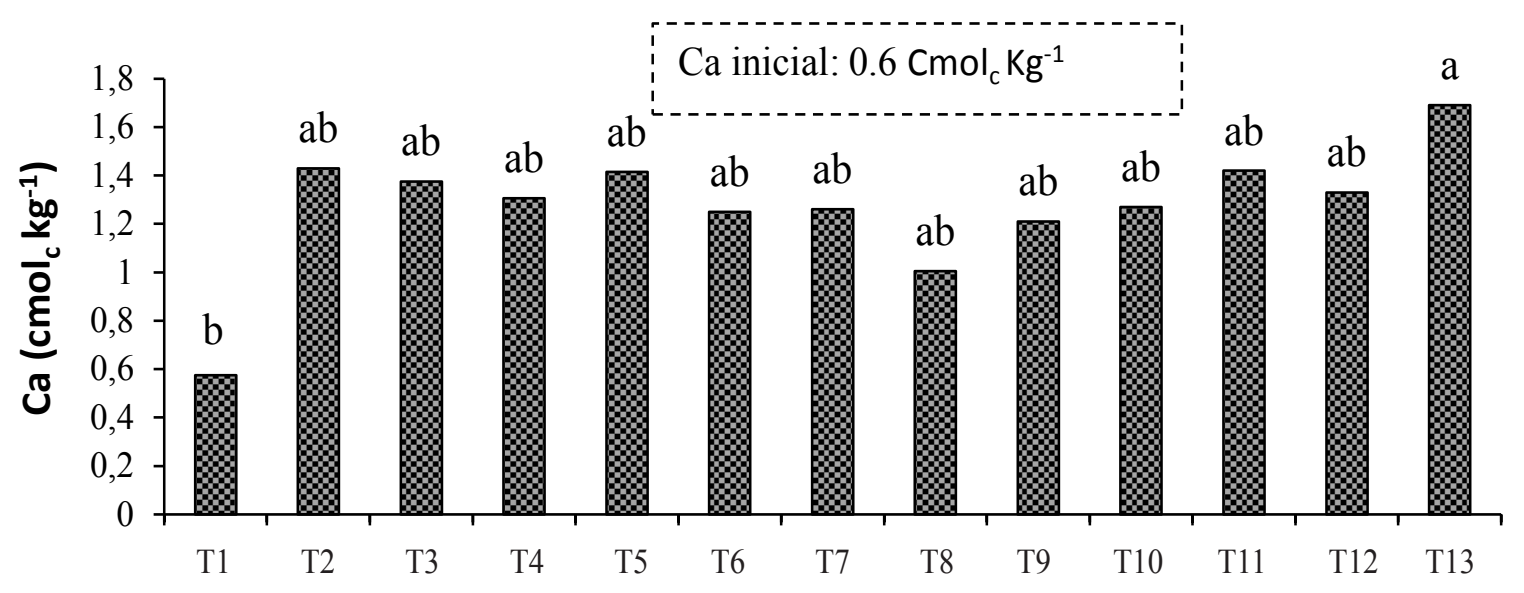

T1: Testigo; T2: dolomita molida; T3: dolomita calcinada; T4: hidróxidos de Ca y Mg; T5: escorias básicas; T6: cal viva; T7: roca fosfórica; T8: gallinaza; T9; dolomita molida, roca fosfórica y gallinaza; T10: dolomita calcinada, roca fosfórica y gallinaza; T11: hidróxidos de Ca y Mg, roca fosfórica y gallinaza; T12: escorias básicas, roca fosfórica y gallinaza; T13: cal viva, roca fosfórica y gallinaza.

Figura 2. Comportamiento del calcio coloidal por efecto de la incorporación al suelo de materiales de encalado después de 40 días de incubación. Medias con la misma letra no difieren significativamente.

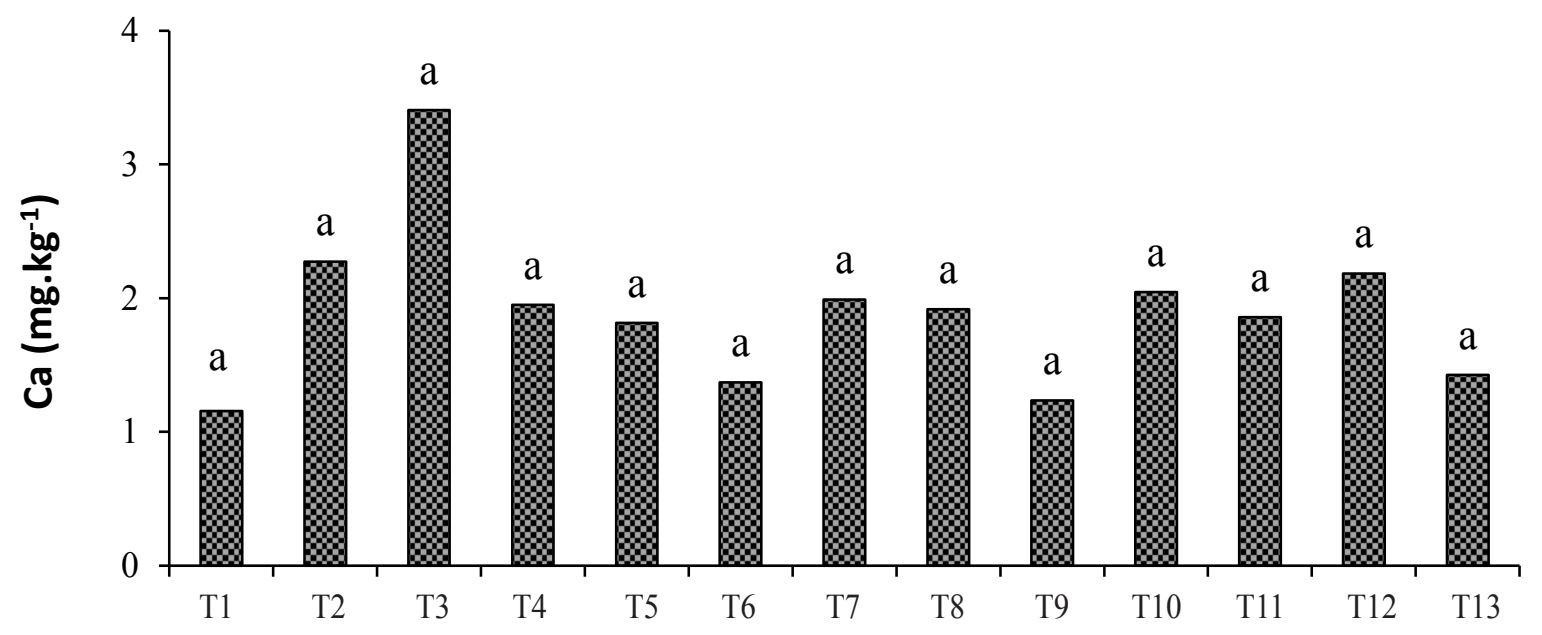

T1: Testigo; T2: dolomita molida; T3: dolomita calcinada; T4: hidróxidos de Ca y Mg; T5: escorias básicas; T6: cal viva; T7: roca fosfórica; T8: gallinaza; T9; dolomita molida, roca fosfórica y gallinaza; T10: dolomita calcinada, roca fosfórica y gallinaza; $\mathrm{T11}$ : hidróxidos de $\mathrm{Ca}$ y $\mathrm{Mg}$, roca fosfórica y gallinaza; $\mathrm{T} 12$ : escorias básicas, roca fosfórica y gallinaza; T13: cal viva, roca fosfórica y gallinaza.

Figura 3. Efecto de materiales de encalado sobre la concentración del Ca soluble en suelo sometido a prueba de incubación por 40 días. Medias con la misma letra no difieren significativamente.

Se observan diferencias altamente significativas de los contenidos de Ca coloidal entre los materiales de encalado explorados experimentalmente como correctivos de acidez y el testigo absoluto donde no se suministraron cales (Figura 2). Lo anterior ratifica lo expuesto por la teoría del encalamiento en el sentido de que esta práctica aporta iones de calcio a la superficie de los coloides, aspecto comprobado por Bullon y Bullon (2014) en un estudio comparativo en suelos oxisoles de Perú y ultisoles de Asia y África. 
No se encontraron diferencias significativas en el contenido de Ca coloidal entre los materiales de encalado sometidos a evaluación (Figura 2). Las mayores concentraciones de Ca extractable o coloidal se registraron en el grupo de los tratamientos (T2, T3, T4, T5, T10, T11, T12, T13), donde sobresale el T13 (mezcla de 75\% cal viva $+10 \%$ roca fosfórica $+15 \%$ gallinaza) con incrementos de $1 \mathrm{Cmol}_{\mathrm{c}} \mathrm{Kg}^{-1}$ de $\mathrm{Ca}$ en el complejo de cambio con respecto al testigo.

El menor valor sobre el aporte de Ca coloidal correspondió al T8 (aplicación de gallinaza), resultado esperado debido a que es un material que aunque su reacción es básica, su composición está lejos de considerarse como material de encalado, sin embargo, después de la incubación se comprobó que existen concentraciones de Ca coloidal muy superiores a los existentes en la condición natural del suelo.

En cuanto al análisis de la concentración de Ca en la solución del suelo no se presentaron diferencias estadísticas significativas entre el testigo (T1) donde no se incorporaron materiales de encalado y los tratamientos experimentales donde sí fueron incorporados (Figura 3). Lo anterior permite deducir que ninguno de los materiales de encalado aportó calcio a la solución del suelo de forma significativa para asumir efecto fertilizante alguno. Es conveniente aclarar que los materiales que han recibido procesos térmicos de calcinación, específicamente la dolomita viva o calcinada (T3), registró con respecto al testigo un aporte de 3,5 mg.kg-1 de Ca a la solución del suelo (Figura $3)$, aunque esta concentración desde el punto de vista agronómico no es relevante frente a la dosis de 1.5t.ha-1. Según Castro y Goméz (2010), este es un aspecto que debe seguir investigándose para resolver interrogantes en el llamado mercado de las fertienmiendas.

Magnesio coloidal y soluble. El contenido de magnesio coloidal, presentó diferencias significativas entre tratamientos (Figura 4). El testigo (T1) fue superado por todos los tratamientos experimentales excepto por (T6, T7, T8, T13) que pertenecen a materiales de encalado no portadores de $\mathrm{Mg}$ en su composición. De otra parte, es fácil identificar la consistencia que se manifiesta en el incremento significativo de los contenidos de Mg en los coloides del suelo cuando se incorporaron materiales de encalado portadores de óxidos e hidróxidos de magnesio (T2, T3, T4, T5, T9, T10, T11, T12), de los cuales se destaca el uso de dolomita calcinada (T3) en razón a que este material presenta un alto contenido de magnesio y un alto equivalente químico en $\mathrm{CaCO}_{3}$ que hace más reactivo el material.

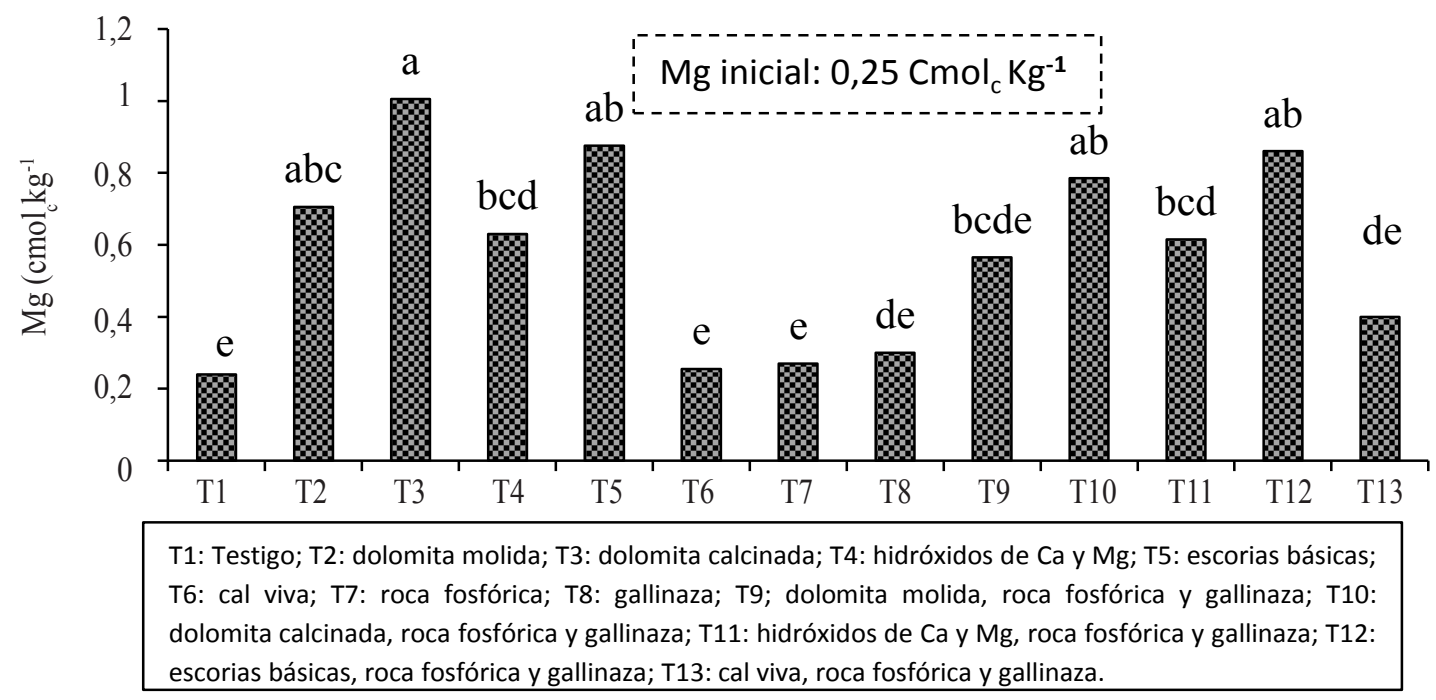

Figura 4. Efecto de materiales de encalado sobre la concentración de Mg coloidal en suelo sometido a prueba de incubación por 40 días. Medias con la misma letra no difieren significativamente. 
Según Castro y Gómez (2010), el efecto del mejoramiento químico de la fracción coloidal del suelo causado por materiales de encalado portadores de magnesio es muy importante para la agricultura moderna en suelos ácidos, entre otras cosas, por el alto potencial de respuesta de estos suelos a las aplicaciones de magnesio debido a su común deficiencia.

El contenido de magnesio soluble, presentó diferencia significativa $(\mathrm{p} \leq 0,05)$ principalmente cuando se compara el testigo con los tratamientos 2 y 3 , relacionados con el uso de dolomitas como rocas molidas o calcinadas (Figura 5). En este caso, con la incorporación de 1.5 t.ha $^{-1} \mathrm{CaCO} 3$ equivalente a través de estos materiales, es posible incrementar los contenidos de Mg soluble respecto al testigo en niveles cercanos a 0,25 $\mathrm{mg} \cdot \mathrm{Kg}^{-1}$, lo que agronómicamente reflejaría en estos materiales un muy bajo efecto fertilizante.

Fósforo disponible. La dinámica del fósforo encontrada en el suelo después de la incorporación e incubación de los materiales de encalado, re- portó un incremento altamente significativo en el fósforo disponible, cuando se utilizó roca fosfórica (Figura 6). Aunque la dosis aplicada como enmienda simple fue de 1.5 t.ha $^{-1}$, se comprueba que el fósforo proveniente de roca fosfórica, teniendo muy baja solubilidad en agua, sí llega al suelo para solubilizarse gradualmente en el tiempo por acción de los propios ácidos del suelo y las bacterias específicas encargadas de este proceso. En un estudio realizado en pruebas de incubacion Basak y Biswas (2015) encontraron que la aplicación de roca fosfórica podría ser utilizada como un material encalante para mejorar la condición del fósforo disponible en suelos ácidos, similar a lo encontrado en el presente estudio. Trabelsi et al. (2017) encontraron un aumento en la actividad microbiana de la rizósfera al incorporar roca fosfórica. Da Costa et al. (2015) muestan que la incubación de bacterias solubilizadoras de fósforo en combinación con la aplicación de roca fosfórica es económico y una estrategia sostenible para mejorar la fertilidad de suelos y la acumulacion de nutrientes en plantas de arroz.

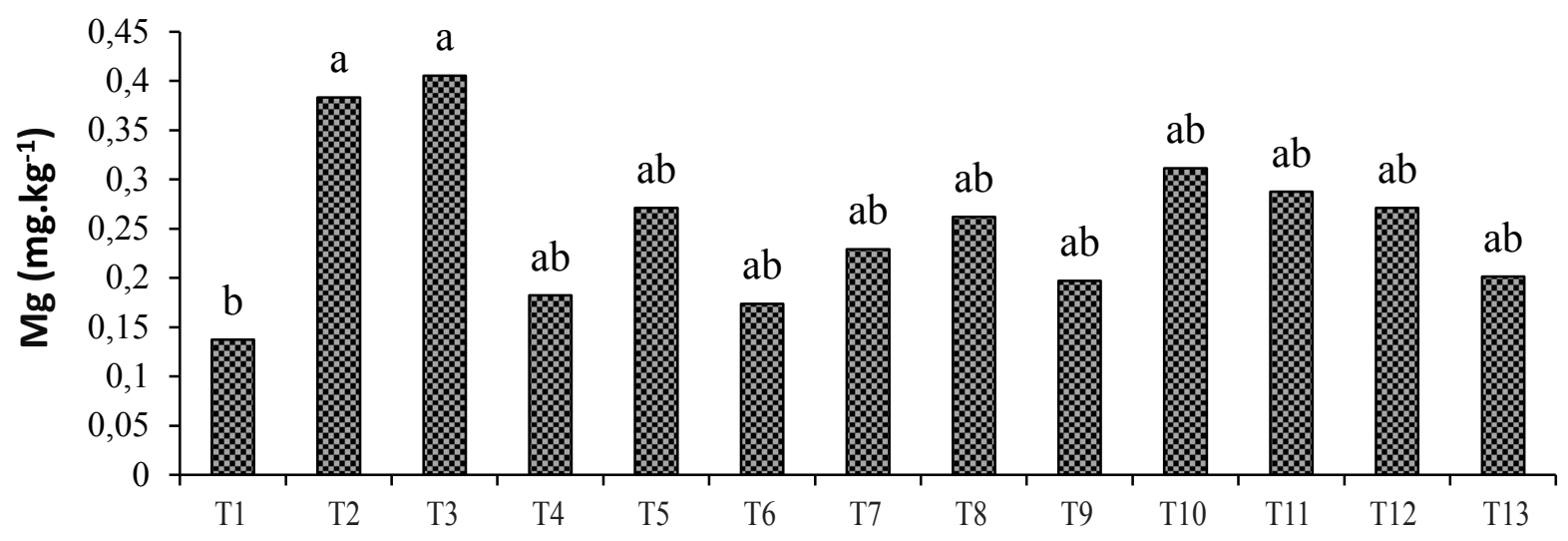

T1: Testigo; T2: dolomita molida; T3: dolomita calcinada; T4: hidróxidos de Ca y Mg; T5: escorias básicas; T6: cal viva; T7: roca fosfórica; T8: gallinaza; T9; dolomita molida, roca fosfórica y gallinaza; T10: dolomita calcinada, roca fosfórica y gallinaza; T11: hidróxidos de Ca y Mg, roca fosfórica y gallinaza; T12: escorias básicas, roca fosfórica y gallinaza; T13: cal viva, roca fosfórica y gallinaza.

Figura 5. Comportamiento del magnesio en la fase soluble del suelo por efecto de los materiales de encalado después de 40 días de incubación. Medias con la misma letra no difieren significativamente. 


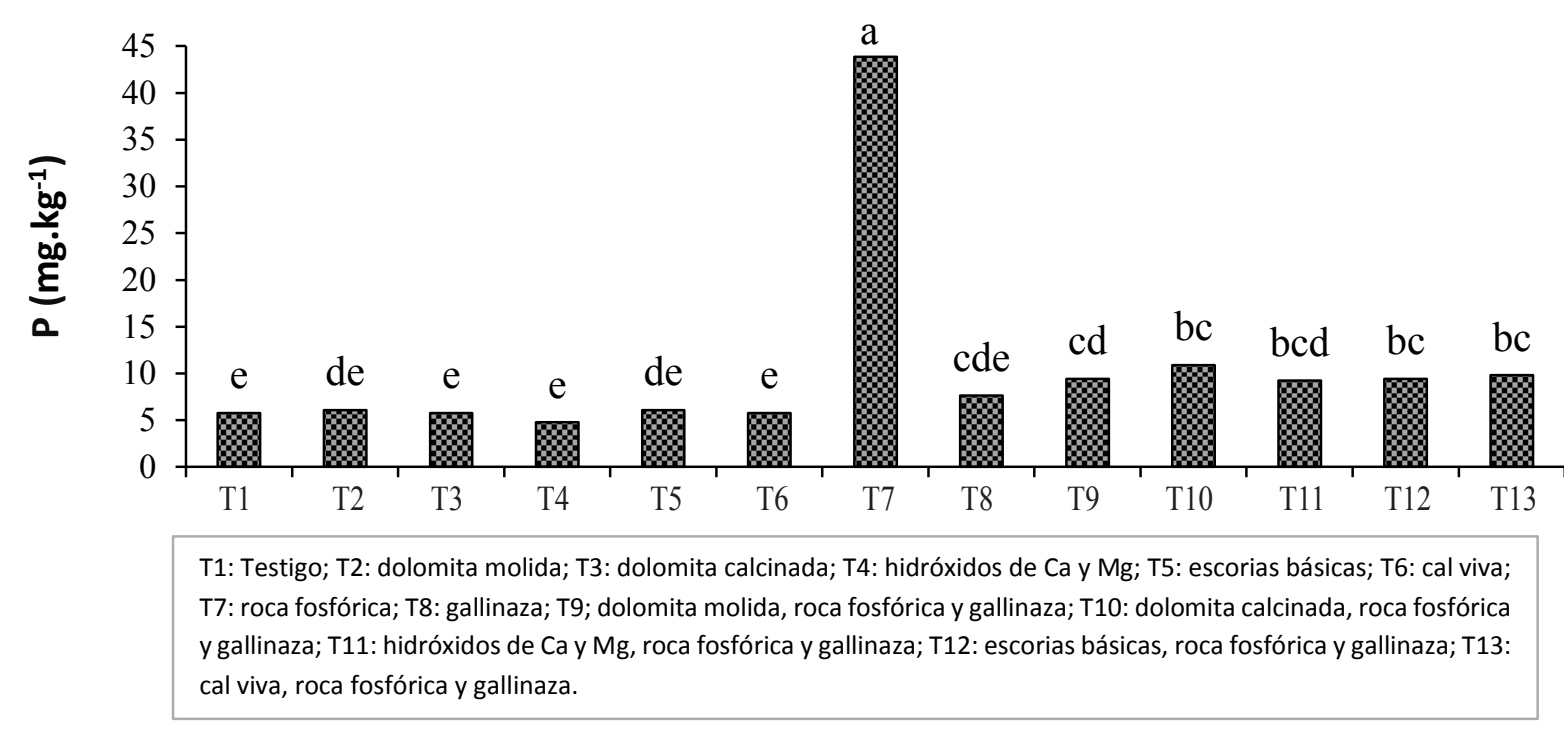

Figura 6. Efecto de la incorporación de materiales de encalado sobre la disponibilidad de fósforo en el suelo después de 40 días de incubación. Medias con la misma letra no difieren significativamente.

Otro resultado que enriquece la discusión sobre el tema del fósforo, es el de que las enmiendas simples de origen calcáreo (T2, T3, T4, T5, T6) se comportaron en forma similar al testigo, dado que no portan fósforo en su composición. Este resultado deja en entredicho, lo que en el marco teórico del control de la acidez se plantea en el sentido del efecto esperado del encalamiento sobre el mejoramiento de los contenidos de fósforo en suelos ácidos.

El grupo de tratamientos referenciado como enmiendas complejas donde participa la roca fosfórica en un 15\% de la mezcla (T8, T9, T10, T11, T12), superó en niveles no significativos, pero sí importantes agronómicamente, los contenidos de fósforo disponible reportados para el testigo absoluto (T1) y el grupo de enmiendas simples de origen calcáreo no portadoras de fósforo. Estos resultados deducen el significado que tiene incluir el uso de la roca fosfórica en el diseño de planes integrales de control de acidez cuando se usan enmiendas complejas, aspecto tratado por Castro y Munevar (2013).

\section{CONCLUSIONES}

Los resultados comprobaron que a la dosis estudiada (1.5 t.ha- ${ }^{-1} \mathrm{CaCO}_{3}$ equivalente) los materiales encalantes usados como enmiendas simples (dolomitas calcinadas, dolomitas molidas, hidróxidos de calcio y magnesio, escorias básicas y cales vivas) presentaron efecto significativo sobre el control de la acidez (activa e intercambiable) y sobre el incremento en la concentración de $\mathrm{Ca}^{2+} \mathrm{y}$ $\mathrm{Mg}^{2+}$ coloidal del suelo estudiado. Similar respuesta se obtuvo cuando los tratamientos relacionados como enmiendas simples, se mezclaron con roca fosfórica y materia orgánica (gallinaza) en la relación porcentual 75:10:15, respectivamente.

El empleo de los hidróxidos de calcio y magnesio (T4, T11) y las escorias básicas de siderúrgica (T5, T12), bien como enmiendas simples o formando parte de enmiendas complejas, ofrecieron efectos superiores en el control de acidez con respecto al resto de materiales. En cuanto al efecto de los materiales de encalado sobre la fracción soluble del suelo se pudo detectar que aunque el contenido de Ca y Mg se ve mejorado en su concentración con respecto al testigo, con diferencias estadísticas 
para el caso de magnesio en dolomitas molidas y calcinadas, agronómicamente esas diferencias no son relevantes. La tendencia de los resultados encontrados sugiere seguir investigando en el tema para concluir sobre el verdadero efecto fertilizante de las enmiendas calcáreas.

Conflicto de intereses: Los autores declaran que no hay conflicto de interés.

\section{REFERENCIAS BIBLIOGRÁFICAS}

Álvarez-Sánchez, M., Hernández-Acosta, E., MaldonadoTorres, R. \& Rivera-González, M. (2013). Lime and mycorrhizae in the phosphorus deficiencies correction in an andisol cultivated with pinus halepensis mill. Madera y Bosques. 19(1): 7-16.

Amézquita, E., Rao, I., Rondón, M., Ayurza, M., Hoyos, P., Molina, D. \& Corrales, I. (2013). Capítulo 13. Mejoramiento de oxisoles de baja fertilidad para sistemas agropastoriles de alta productividad en sabanas tropicales de Colombia. pp. 198-218. En: Amézquita, E., Rao, I., Rivera, M., Corrales, I., Bernal. (eds). Sistemas agropastoriles: Un enfoque integrado para el manejo sostenible de Oxisoles de los Llanos orientales de Colombia. $1_{\mathrm{a}}$ ed. Cali, Colombia: Centro Internacional de Agricultura Tropical (CIAT); Ministerio de Agricultura y Desarrollo Rural (MADR) de Colombia; Corporación Colombiana de Investigación Agropecuaria (Corpoica). 288p.

Basak, B. \& Biswas, D. (2015). Potentiality of indian rock phosphate as liming material in acid soil. Geoderma. 263: 104-109. doi: 10.1016/j. geoderma.2015.09.016.

Bullon, J. \& Bullon, C. (2014). Estudio comparativo de la mineralogía y los coloides arcillosos en suelos de trópicos húmedos. Apunt. Cienc. Soc. 4(2): 222-231. doi: 10.18259/acs.2014026.

Carmeis, A., Penn, C., Crusciol, C. \& Calonego, J. (2017). Lime and phosphogypsum impacts on soil organic matter pools in atropical oxisol under longterm no-till conditions. Agriculture, Ecosystems \& Environment. 241(1): 11-23. doi: 10.1016/j. agee.2017.02.027.
Castro, H. \& Gómez, M. (2015). Suelos Sulfatados Ácidos. El caso del Valle Alto del río Chicamocha, Boyacá - Colombia. Libro producto de investigación Grupo Interinstitucional de Investigación en Suelos Sulfatados Ácidos Tropicales, Gissat- Uptc - Colciencias. ISBN 978-958-660-213-6. Editorial Uptc. 270p.

Castro, H., Gómez, M., Munevar, 0. \& Hernandez, D. (2006). Diagnóstico y control de la acidez en suelos sulfatados acidos en el distrito de riego del alto chicamocha (boyaca) mediante pruebas de incubacion. Agronomia Colombiana. 24(1): 122130.

Castro, H. \& Munevar, Ó. (2013). Mejoramiento químico de suelos ácidos mediante el uso combinado de materiales encalantes. U.D.C.A Actualidad \& Divulgación Científica. 16(2): 409-416.

Castro, H. \& Gómez, M. (2010). Capítulo 4. Fertilidad de suelos y fertilizantes. pp. 217- 298. En: Burbano, 0. \& Silva, M. (eds). Ciencia del suelo principios básicos. Primera edición. Bogotá DC: .Editorial Guadalupe S.A.

Da Costa, E., De Lima, W., Oliveira-Longatti, S. \& De Souza, F. (2015). Phosphate-solubilising bacteria enhance Oryza sativa growth and nutrient accumulation in an oxisol fertilized with rock phosphate. Ecological Engineering. 83: 380-385. doi: 10.1016/j.ecoleng.2015.06.045.

Epstein, E. \& Bloom, A. (2005). Mineral nutrition of plants: principles and perspectives. Sunderland, Massachusetts: Sinauer Associates, Inc. Publishers. 380p.

Hagvall, K., Persson, P. \& Karlsson, T. (2015). Speciation of aluminium in soil and stream waters: the importance of organic matter. Chemical Geology. 417: 32-43. doi: 10.1016/j.chemgeo.2015.09.012.

Lora, R. (2010). Capítulo 2: Propiedades químicas del suelo. pp. 77- 134. En: Burbano, 0. \& Silva M F (eds). Ciencia del suelo principios básicos. Primera edición. Bogotá DC: Editorial Guadalupe S.A.

Marschner, H. (1995). Mineral nutrition of higher plants. Second edition. London: Academic Press. 889p. doi: 10.1006/anbo.1996.0155. 
Materechera, S. \& Mkhabela, T. (2002). The effectiveness of lime, chicken manure and leaf litter ash in ameliorating acidity in a soil previouslyunder black wattle (Acacia mearnsii) plantation. Bioresourse Technology. 85 (1): 9-16. doi:10.1016/S09608524(02)00065-2.

Massao, T., Moraes, J., Fávero, E. \& Potma, D. (2016). Lime and gypsum application increases biological activity, carbon pools, and agronomic productivity in highly weathered soil. Agriculture. Ecosystems and Environment. 231: 156-165. doi: 10.1016/j. agee.2016.06.034.

Masud, M., Jiu-Yu, L. \& Ren-Kou, X. (2014). Use of alkaline slang and crop reside biochars to base saturation and reduce acidity of an acidotic ultisol. Pedosphere. 24 (6): 791-798.

Rivera, M., Amézquita, E., Bernal, J. \& Rao, M. (2013). Capítulo 1. Las sabanas de los Llanos Orientales de Colombia: Caracterización biofísica e importancia para la producción agropecuaria. pp. 3-10. En: Amézquita, E., Rao, I., Rivera, M., Corrales, I. \& Bernal. (eds). Sistemas agropastoriles: Un enfoque integrado para el manejo sostenible de Oxisoles de los Llanos orientales de Colombia. Primera edición. Cali, Colombia: Centro Internacional de Agricultura Tropical (CIAT); Ministerio de Agricultura y Desarrollo Rural (MADR) de Colombia; Corporación Colombiana de Investigación Agropecuaria (Corpoica). 288p.

Sarma, B., Borkotoki, B., Narzari, R. \& Kataki, N. (2017). Organic amendments: effect on carbon mineralization and crop productivity in acid soil. Journal of Cleaner Production. 152: 157-166. doi: 10.1016/j.jclepro.2017.03.124.

Soil Survey Staff. (2014). Keys to soil taxonomy. Twelfth edition. Washington, D.C: United States Department of Agriculture, Natural Resources Conservation Service. 372p.

Souza, I., Archanjo, B., Hurtarte, L., Oliveros, M., Gouvea, C., Lidizio, L., Achate, C., Schaefer, C. \& Silva, I. (2017). Al-/Fe-(hydr) oxides-organic carbon associations in oxisols - from ecosystems to submicron scales. Catena. 154: 63-72. doi: 10.1016/j.catena.2017.02.017.
Trabelsi, D., Cherni, A., Zineb, A., Fitoiri, S. \& Mhamdi, R. (2017). Fertilization of Phaseolus vulgaris with the Tunisian rock phosphate affects richness and structure of rhizosphere bacterial communities. Applied soil Ecology. 114: 1-8. doi: 10.1016/j. apsoil.2016.11.014.

Wang, L., Yang, X., Rachel, K., Wang, Y., Tong, D., Ye, M. \& Jiang, X. (2013). Combined use of alkaline slag and rapeseed cake to ameliorate soil acidity in an acid tea garden soil. Pedosphere. 23 (2): 177-184. 